\title{
Comparison of the Resistance of Soild Shell of Composite Materials with other Soild Metal Materials
}

\author{
${ }^{1}$ Majid Kalel Najim , ${ }^{2}$ Jamal Nayief Sultan, ${ }^{3}$ Emad Toma Karash \\ \{dr.majid.najim@gmail.com ${ }^{1}$, Jamalnayyef20@gmail.com ${ }^{2}$, emadbane2007@ntu.edu.iq $\left.{ }^{3}\right\}$ \\ 1,2,3 Northern Technical University - Iraq
}

\begin{abstract}
Recently, in connection with the increasing use of composite materials in various fields of modern technology, interest in theories of reinforced media and new technologies for their manufacture has significantly increased. Twenty-seven models were designed from metallic materials, one from aluminum, one from steel, and the third was composed of five layers, three from Epoxy and two from Steel. As for the non-metallic models, three models were made of fiberglass with different codes and three other models of epoxy with carbon fibers and also with different codes. All models are equal in weight, height and width but different in thickness. Three types of loads were shed in the middle of the models. The results of the comparison between the different models, after analyzing the results, indicate that the best model that can withstand the loads imposed on it is the model of composite materials (CFGR - Code2), while the worst model is the model of steel. The results of the analysis also indicate the effect of the change in the overload on the models is directly proportional to the same percentage change in the overload on the models, whether the models are composed of ferrous or non-ferrous materials composite materials.
\end{abstract}

Keywords: Carbon fiber, steel, fiber glass, composite materials, failure, tensile stress.

\section{Introduction}

Carbon fabric reinforced composites have been widely used in manufacturing due to their hardly melting at high temperature, and high strength embedded in thermoset or thermoplastic polymeric matrix $[1,2]$. Vinyl ester resin after reinforcing with glass fibers showed a high tensile and flexural strength due to high elastic modulus and the strength was increased with an increase in the fibers percentage [3]. Various composite materials used in bulletproof vests were studied to analyze their effectiveness against bullet force [4]. The bullet impact energy that has been transmitted to the vest is absorbed and scattered by the very strong fibers in composite materials, and that absorption results to deformation or "mushroom" of the bullet, and successively each layer of the best material was also absorbing the additional energy of the bullet. The high tensile strength of Vinyle ester resin was shown due to the high elastic modulus of the composite material [5]. Hossein Rahmani et al [6] studied the mechanical properties of epoxy resin composites strengthened with carbon fiber to explore the influence of $\left(0^{\circ}, 35^{\circ}, 45^{\circ}\right.$, and $\left.90^{\circ}\right)$ angle fiber orientation. Their mechanical properties result from the viewpoint of tensile, impact, and bending strength was depending mainly on the fiber orientation followed by the lamination amount. Mechanical behavior composition of carbon glass fiber that reinforced by epoxy composite have been performed by Ozsoy et al [7] to research bending as well as tensile properties for both Carbon Fiber (CFRE) and Glass Fiber Reinforced Epoxy (GFRE) for $\left(0^{\circ}, 90^{\circ}\right.$, and $\left.\left[0^{\circ}, 90^{\circ}\right]\right)$ fiber direction. They concluded that the greatest tensile strength was found with the fiber direction of $0^{\circ}$ for the two composites CFRE as well as GFRE. Ballistic protection evaluation of sequencing the composite material sandwich panels for the reliable combination of Armor layers was studied by Yilmazcoban and Doner [8]. Their results showed that polymer utilized between the armed and the aluminum honeycomb sandwich panel reinforced by carbon fiber was the most accurate and reliable of the tests as well as a computer simulation. The behavior of the composite laminate was studied for impact load [9]. Carbon fiber reinforced composite and boron fiber 
reinforced composite was tested and the material was shown to exhibit complex failure behavior under impact loading. The effect of graphite filler of different amounts (ranging from 5 to $3 \mathrm{wt} \%$ ) on the mechanical properties of both epoxy reinforced with carbon fiber as well as epoxy resin composites were studied by Ricardo Baptista et al [10]. It was found that the increase in graphite filler contents results in an improvement in the epoxy matrix tensile modulus. It was also shown that graphite materials by $7.5,10$, and 11.5 weight $\%$ revealed an increase in the finite stress value with an increase in the amount of filler, and the tensile modulus was enhanced by the introduction of the reinforcing carbon fiber. Mechanical and impact test of Carbon Fiber reinforced Polymer (CFRP) was studied by Cathrine HØgmo Strand [11]. An air gun impact test was performed as well as the Charpy impact test to evaluate the fracture toughness. It was shown an overall degradation of the mechanical properties of the CFRP when exposed to cold temperatures. The ballistic impact response of aluminum alloys hybridized with Kevlar / Epoxy composites was studied by Eyüp Yeter [12]. The results showed that a hybrid model with 6AL - 6KEV orientation, was the optimum structure to resist the ballistic impact loading. Compression and tensile properties of the interlayer, as well as interlayer hybrid composites, have been investigated by Weili Wu et al [13]. It was concluded that the hybrid composites tensile fracture strain was greater than the compression fracture strain. Exploratory testing and modeling of the ballistic effect on composite laminated equipment consist of three layers of various materials: cemented fiber, Kelven fabric as well as steel [14]. A bullet of $9 \mathrm{~mm}$ FMJ was launched like $100 \mathrm{~cm} 2$ armor on the fiber-cement side. The results of the experimental tests and simulations were contrasted to investigate the conduct of the folded armored structure, and good agreement was reached.

\section{Materials and Model analysis}

A 3D Finite Element model was created to simulate impact test in ANSYS 15.1, figure (1) shown the models. Three different pressures were taken to applied on the sample which are 40,80 and $120 \mathrm{kN} / \mathrm{m}^{2}$.

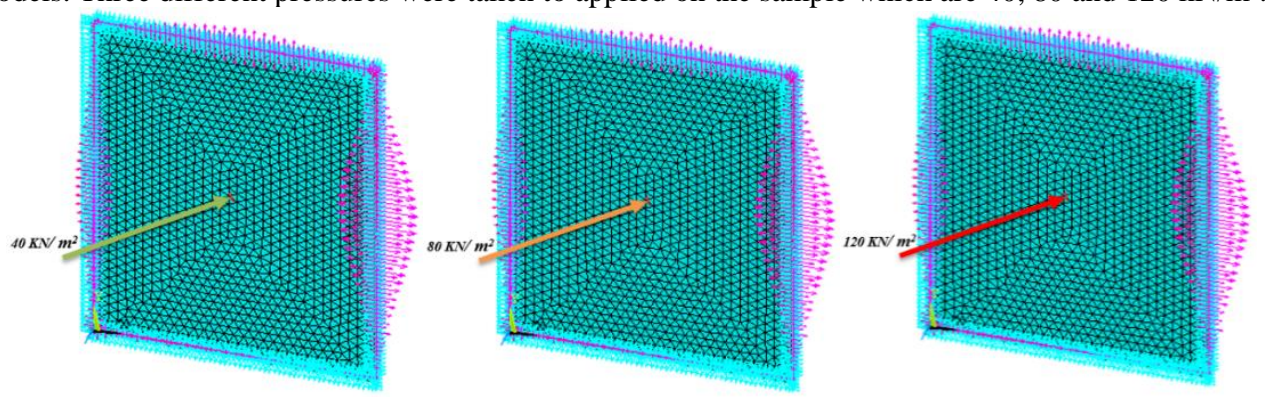

Fig. 1. Solid shell geometry.

Numerical simulations were performed based on the laboratory conditions used in a practical test for the impact test where we take into account the shape and geometry of the sample process and the boundary conditions. We will focus on two main aspects of this procedure. Modeling the sample, and calculating stresses on failure. Simulations were performed using ANSYS structural (15.1). Nine models were designed from different materials with the purpose of comparing the stresses affecting them. The models chosen are: Aluminum, Steel, Steel \& Epoxy, Three models Carbon fiber and three models Fiberglass. Three codes were selected for the Fiberglass and Carbon fiber model as show in figure 2. 


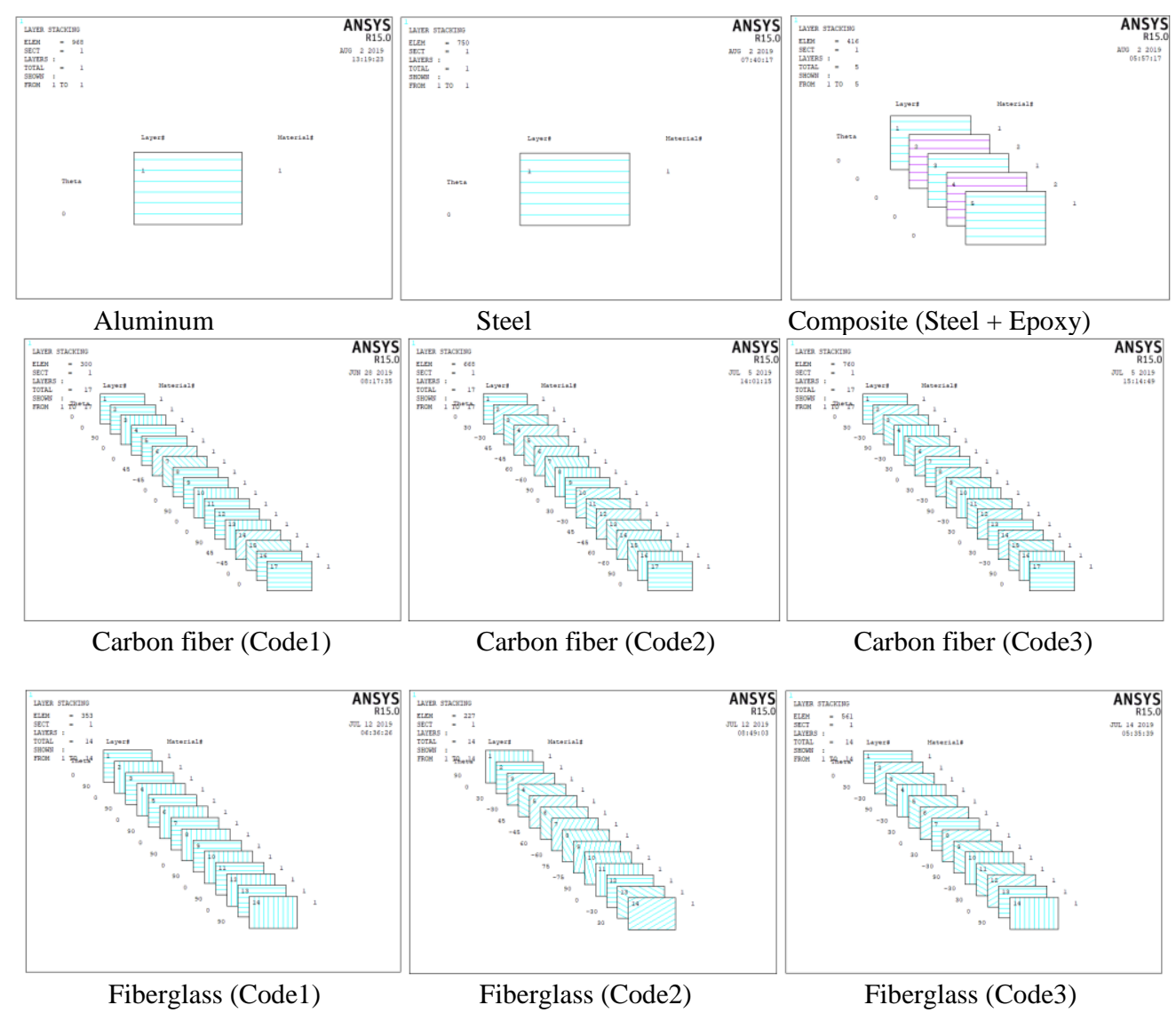

Fig. 2. Show codes of all models.

Table 1 shows the specifications of the materials used in the model structures, while table 2 shows Elastic characteristics of carbon fiber - and fiberglass. Table .3 shows the specifications used to draw test samples and codes of materials used in all tests.

Table 1. Elastic characteristics of carbon fiber - and fiberglass

\begin{tabular}{|c|c|c|c|c|c|c|c|c|c|}
\hline No. & \multicolumn{2}{|l|}{ Material } & $\begin{array}{l}\text { Density } \\
\rho, K g / \mathrm{m}^{3}\end{array}$ & $\begin{array}{l}\text { Modulus } \\
\text { of } \\
\text { elasticity } \\
E, G P a\end{array}$ & $\begin{array}{l}\text { Passion } \\
\text { ratio }\end{array}$ & $\begin{array}{l}\text { Heig } \\
\text { ht, } \\
(\mathbf{m m})\end{array}$ & $\begin{array}{l}\text { Width } \\
w, \\
(m m)\end{array}$ & $\begin{array}{l}\text { Thickness } \\
t \text {, } \\
(\mathrm{mm})\end{array}$ & $\begin{array}{l}\text { Weigh } \\
\mathrm{t} \\
W, \\
(\mathrm{Kg}) \\
\end{array}$ \\
\hline 1 & \multicolumn{2}{|l|}{ Aluminum } & 2700 & 70 & 0.33 & \multirow{7}{*}{500} & \multirow{7}{*}{400} & 10 & \multirow{7}{*}{5.4} \\
\hline 2 & \multicolumn{2}{|l|}{ Steel } & 7800 & 210 & 0.3 & & & 3.5 & \\
\hline \multirow{2}{*}{3} & \multirow{2}{*}{$\begin{array}{l}\text { Carbon } \\
\text { fiber }\end{array}$} & Carbon & 1800 & 3.5 & & & & \multirow{2}{*}{17} & \\
\hline & & Epoxy & 1200 & 4.2 & 0.3 & & & & \\
\hline \multirow{2}{*}{4} & \multirow{2}{*}{ Fiberglass } & Glass & 2500 & 3.4 & 0.2 & & & \multirow{2}{*}{14} & \\
\hline & & Epoxy & 1200 & 3.5 & 0.3 & & & & \\
\hline 5 & Compsite & Steel & 7750 & 200 & 0.3 & & & 2 & \\
\hline
\end{tabular}




\begin{tabular}{|}
\hline \\
\begin{tabular}{|l|l|l|l|l|l|l|l|}
\hline & Epoxy & 1200 & 4.2 & 0.3 & & 9.66 \\
\hline Taterial & $\mathrm{E}_{\mathrm{ii}}, \mathrm{MPa}$ & $\mathrm{G}_{\mathrm{ii}}, \mathrm{MPa}$ & $\mathrm{v}_{\mathrm{ij}}$ & $\mathrm{v}_{\mathrm{ji}}$ \\
\hline \multirow{4}{*}{ Carbon fiber } & $\mathrm{E}_{11}=9100 \mathrm{C}$ & $\mathrm{G}_{12}=1154 \mathrm{C}$ & $\mathrm{v}_{12}=0,26$ & $\mathrm{v}_{21}=0,110$ \\
& $\mathrm{E}_{22}=3870($ & $\mathrm{G}_{13}=2750$ & $v_{13}=0,30$ & $v_{31}=0,028$ \\
& $\mathrm{E}_{33}=8590$ & $\mathrm{G}_{23}=1070$ & $v_{23}=0,30$ & $v_{32}=0,067$ \\
\hline \multirow{5}{*}{ Fiberglass } & $\mathrm{E}_{11}=2660 \mathrm{C}$ & $\mathrm{G}_{12}=5030$ & $v_{12}=0,17$ & $v_{21}=0,150$ \\
& $\mathrm{E}_{22}=2330($ & $\mathrm{G}_{13}=1140$ & $v_{13}=0,52$ & $v_{31}=0,062$ \\
& $\mathrm{E}_{33}=1076 \mathrm{C}$ & $\mathrm{G}_{23}=950$ & $v_{23}=0,53$ & $v_{32}=0,245$ \\
\hline
\end{tabular}
\end{tabular}

Table 3. Specifications used to draw test samples.

\begin{tabular}{|c|c|c|c|c|c|}
\hline No. & Material & $\begin{array}{c}\text { Number } \\
\text { of Layers }\end{array}$ & Code & Model & $\begin{array}{c}\text { Type of } \\
\text { Element }\end{array}$ \\
\hline 1 & Aluminum & 1 & {$[0]$} & Linear & \multirow{9}{*}{$\begin{array}{l}\text { Solid } 187 \\
\text { Geometry } \\
, 10 \text { Nods } \\
\text {,3-D } \\
\text { Modeling }\end{array}$} \\
\hline 2 & Steel & 1 & [0] & Linear & \\
\hline 3 & $\begin{array}{l}\begin{array}{l}\text { Carbon } \\
(\text { Code1 })\end{array} \\
\end{array}$ & 17 & {$\left[0_{2} / 90 / 0_{2} / \pm 45 / 0_{2} / 90 / 0_{2} / 90 / \pm 45 / 0_{2}\right]$} & Linear & \\
\hline 4 & $\begin{array}{l}\text { Carbon fiber } \\
(\text { Code2) }\end{array}$ & 17 & $\begin{array}{c}{[0 / \pm 30 / 90 / \mp 30 / 0 / \pm 30 / 90 / \mp 30 / 0 / \pm 30 / 90} \\
/ 0]\end{array}$ & Linear & \\
\hline 5 & $\begin{array}{l}\text { Carbon fiber } \\
(\text { Code3) }\end{array}$ & 17 & {$[0 / \pm 30 / \pm 45 / \pm 60 / 90 / 0 / \pm 30 / \pm 45 / \pm 60 / 90 / 0]$} & Linear & \\
\hline 6 & $\begin{array}{l}\text { Fiberglass } \\
\text { (Code1) }\end{array}$ & 14 & {$[0 / 90 / 0 / 90 / 0 / 90 / 0 / 90 / 0 / 90 / 0 / 90 / 0 / 90]$} & Linear & \\
\hline 7 & $\begin{array}{l}\text { Fiberglass } \\
\text { (Code2) }\end{array}$ & 14 & {$[90 / 0 / \pm 30 / \pm 45 / \pm 60 / \pm 75 / 90 / 0 / \pm 30]$} & Linear & \\
\hline 8 & $\begin{array}{l}\text { Fiberglass } \\
\text { (Code3) }\end{array}$ & 14 & {$[0 / \pm 30 / 90 / \mp 30 / 0 / \pm 30 / 90 / \mp 30 / 90 / 0]$} & Linear & \\
\hline 9 & $\begin{array}{l}\text { Composite } \\
\text { (Steel + Epoxy) }\end{array}$ & 5 & {$[0 / 0 / 0 / 0 / 0]$} & Linear & \\
\hline
\end{tabular}

\section{Results and discussion}

In this result the material of the sample is altered to cover many materials. The materials used for the sample are Aluminum, Steel and Epoxy, Carbon Fiber Reinforced Polymer and Glass Fiber Polymer. The program used for processing is the ANSYS R15.0 to get the theoretical results for deformed + Undeformed shape, Displacement vector sum, stress (z-component of stress), Stress intensity, Von Mises stresses, Total mechanical strain and Failure Criteria (maximum stress). These results taken for three values of pressure applied on the sample which are 40,80 and $120 \mathrm{kN} / \mathrm{m}^{2}$.

In table (4-1) and figure (3) the displacement of deformed shape for $40 \mathrm{kN} / \mathrm{m}^{2}$ are shown for the materials of the sample discussed previously. The maximum displacement occurred in steel sample which is $8.64 * 10^{-6} \mathrm{~m}$. while the minimum value occurred when the material is Carbon Fiber Reinforced Polymer which is $4.1^{*} 10^{-11} \mathrm{~m}$, and this means that the Carbon fiber is the highest strength.

Table (4-2) and figure (4) show the displacement vector sum for all sample materials taken with pressure $40 \mathrm{kN} / \mathrm{m}^{2}$. The maximum displacement occurred when the sample material is Aluminum which is $1.07 * 10^{-6} \mathrm{~m}$. While the minimum value for displacement when the sample material is Carbon Fiber reinforced polymer $\left(1.65^{*} 10^{-14} \mathrm{~m}\right)$. And that because of the connection occurred as a result of the Reinforced Fiber. 
Table (4-3) and figure (5) show the stress(z-component). The maximum value of this stress is ( $8.64 * 10^{-6} \mathrm{~N} / \mathrm{m}^{2}$ ), which is very small stress happened when the sample material is Steel.

Table (4-4) and figure (6) show shows the stress intensity factor for all sample materials. The maximum value of this intensity is for Steel sample which is $\left(857272 \mathrm{~N} / \mathrm{m}^{2}\right)$. While minimum value of this intensity is for Glass Fiber Reinforced $\left(1.11 \mathrm{~N} / \mathrm{m}^{2}\right)$.

Table (4-5) and figure (7) show the Von Mises stress for all material samples. And the maximum Von Mises stress value is occurred when the sample material is Steel which is $\left(828052 \mathrm{~N} / \mathrm{m}^{2}\right)$.

Table (4-6) and figure (8) show the mechanical strain in Z-direction for all sample materials. The maximum strain happened when the sample material is Steel and Epoxy with the value is $\left(2.73 * 10^{-6} \mathrm{~m}\right)$. Table (4-7) and figure (9) show the results of maximum stress for failure criteria. The maximum value of this stress occurred when the sample material is Steel.

All these experiments are repeated when the pressure applied on the sample became $\left(80 \mathrm{kN} / \mathrm{m}^{2}\right)$ and then altered to $\left(120 \mathrm{kN} / \mathrm{m}^{2}\right)$. And all the previous values in the figures above were increased when increasing the pressure applied at the sample.

Table 4. shows comparison of stress analysis.

\begin{tabular}{|c|c|c|c|c|c|c|c|c|c|}
\hline \multicolumn{10}{|c|}{ 1- Deformed Shape (Def + Undeformed(meter)) } \\
\hline \multirow{2}{*}{$\begin{array}{l}\text { Pressure } \\
K N / m^{2}\end{array}$} & \multirow{2}{*}{ Aluminum } & \multirow{2}{*}{ Steel } & \multirow{2}{*}{$\begin{array}{c}\text { Steel } \\
\& \\
\text { Epoxy }\end{array}$} & \multicolumn{3}{|c|}{ CFRP } & \multicolumn{3}{|c|}{ GFR } \\
\hline & & & & Code 1 & Code 2 & Code 3 & Code 1 & Code 2 & Code 3 \\
\hline 40 & $1.07 * 10^{-6}$ & $8.64 * 10^{-6}$ & $2.98 * 10^{-6}$ & $4.77 * 10^{-11}$ & $4.10 * 10^{-11}$ & $4.17 * 10^{-11}$ & $12.9 * 10^{-11}$ & $8.90 * 10^{-11}$ & $9.22 * 10^{-11}$ \\
\hline 80 & $2.13 * 10^{-6}$ & $173 * 10^{-6}$ & $596 * 10^{-6}$ & $9.53 * 10^{-11}$ & $8.21 * 10^{-11}$ & $8.34 * 10^{-11}$ & $25.8 * 10^{-11}$ & $17.8 * 10^{-11}$ & $18.4 * 10^{-11}$ \\
\hline 120 & $3.20 * 10^{-6}$ & $259 * 10^{6}$ & $894 * 10^{-6}$ & $14.3 * 10^{-11}$ & $12.3 * 10^{-11}$ & $12.5 * 10^{-11}$ & $18.3 * 10^{-11}$ & $26.7 * 10^{-11}$ & $27.7^{*} 10^{-11}$ \\
\hline
\end{tabular}

\begin{tabular}{|c|c|c|c|c|c|c|c|c|c|}
\hline \multicolumn{10}{|c|}{ 2- Displacement vector sum (meter)) } \\
\hline \multirow{2}{*}{$\begin{array}{l}\text { Pressure } \\
\mathrm{KN} / \mathrm{m}^{2}\end{array}$} & \multirow{2}{*}{ Aluminum } & \multirow{2}{*}{ Steel } & \multirow{2}{*}{$\begin{array}{c}\text { Steel } \\
\& \\
\text { Epoxy }\end{array}$} & \multicolumn{3}{|c|}{ CFRP } & \multicolumn{3}{|c|}{ GFR } \\
\hline & & & & Code 1 & Code 2 & Code 3 & Code 1 & Code 2 & Code 3 \\
\hline 40 & $1.07 * 10^{-6}$ & $8.64 * 10^{-5}$ & $2.98 * 10^{-5}$ & $4.77 * 10^{-11}$ & $4.10 * 10^{-11}$ & $4.17 * 10^{-11}$ & $12.9 * 10^{-11}$ & $8.90 * 10^{-11}$ & $9.22 * 10^{-11}$ \\
\hline 80 & $2.13 * 10^{-6}$ & $17.3 * 10^{-5}$ & $5.96 * 10^{-5}$ & $9.53 * 10^{-11}$ & $8.21 * 10^{-11}$ & $8.34 * 10^{-11}$ & $25.8 * 10^{-11}$ & $17.8 * 10^{-11}$ & $18.4 * 10^{-11}$ \\
\hline 120 & $3.20 * 10^{-6}$ & $25.9 * 10^{-5}$ & $8.94 \times 10^{-5}$ & $14.3 * 10^{-11}$ & $12.3 * 10^{-11}$ & $12.5 * 10^{-11}$ & $18.3 * 10^{-11}$ & $26.7 * 10^{-11}$ & $27.7 * 10^{-11}$ \\
\hline
\end{tabular}

\begin{tabular}{|c|c|c|c|c|c|c|c|c|c|}
\hline \multicolumn{10}{|c|}{ 3- Stress ( Z-Component of stress $\left(\mathrm{N} / \mathrm{m}^{2}\right)$} \\
\hline \multirow{2}{*}{$\begin{array}{l}\text { Pressure } \\
K N / \boldsymbol{m}^{2}\end{array}$} & \multirow{2}{*}{ Aluminum } & \multirow{2}{*}{ Steel } & \multirow{2}{*}{$\begin{array}{l}\text { Steel } \\
\& \\
\text { Epoxy }\end{array}$} & \multicolumn{3}{|c|}{ CFRP } & \multicolumn{3}{|c|}{ GFR } \\
\hline & & & & Code 1 & Code 2 & Code 3 & Code 1 & Code 2 & Code 3 \\
\hline 40 & $1.07 * 10^{-5}$ & $8.64 * 10^{-5}$ & $2.98 * 10^{-5}$ & $4.77 * 10^{-11}$ & $4.10 * 10^{-11}$ & $4.17 * 10^{-11}$ & $12.9 * 10^{-11}$ & $8.90 * 10^{-11}$ & $9.22 * 10^{-11}$ \\
\hline 80 & $2.13 * 10^{-5}$ & $17.3^{*} 10^{-5}$ & $5.96 * 10^{-5}$ & $9.53 * 10^{-11}$ & $8.21 * 10^{-11}$ & $8.34{ }^{*} 10^{-11}$ & $25.8 * 10^{-11}$ & $17.8 * 10^{-11}$ & $18.44^{*} 0^{-11}$ \\
\hline 120 & $3.20 * 10^{-5}$ & $25.9 * 10^{-5}$ & $8.94 * 10^{-5}$ & $14.3 * 10^{-11}$ & $12.3 * 10^{-11}$ & $12.5 * 10^{-11}$ & $18.3 * 10^{-11}$ & $26.7 * 10^{-11}$ & $27.7 * 10^{-11}$ \\
\hline
\end{tabular}




\begin{tabular}{|c|c|c|c|c|c|c|c|c|c|}
\hline \multicolumn{10}{|c|}{ 4- Stress intensity } \\
\hline \multirow{2}{*}{$\begin{array}{l}\text { Pressure } \\
K N / m^{2}\end{array}$} & \multirow{2}{*}{ Aluminum } & \multirow{2}{*}{ Steel } & \multirow{2}{*}{$\begin{array}{c}\text { Steel } \\
\& \\
\text { Epoxy }\end{array}$} & \multicolumn{3}{|c|}{ CFRP } & \multicolumn{3}{|c|}{ GFR } \\
\hline & & & & Code 1 & Code 2 & Code 3 & Code 1 & Code 2 & Code 3 \\
\hline 40 & 104805 & 857272 & 15000.1 & 408.678 & 468.054 & 427.171 & 537.488 & 997.353 & 627.024 \\
\hline 80 & 209609 & 1710000 & 30000.3 & 817.356 & 0.936107 & 854.343 & 1074.98 & 1994.71 & 1254.05 \\
\hline 120 & 314414 & 2570000 & 45000.4 & 1226.03 & 1404.16 & 1281.51 & 1254.9 & 2992.06 & 188107 \\
\hline
\end{tabular}

\begin{tabular}{|c|c|c|c|c|c|c|c|c|c|}
\hline \multicolumn{10}{|c|}{ 5- Von Mises stress } \\
\hline \multirow{2}{*}{$\begin{array}{l}\text { Pressure } \\
K N / m^{2}\end{array}$} & \multirow{2}{*}{ Aluminum } & \multirow{2}{*}{ Steel } & \multirow{2}{*}{$\begin{array}{c}\text { Steel } \\
\& \\
\text { Epoxy }\end{array}$} & \multicolumn{3}{|c|}{ CFRP } & \multicolumn{3}{|c|}{ GFR } \\
\hline & & & & Code 1 & Code 2 & Code 3 & Code 1 & Code 2 & Code 3 \\
\hline 40 & 101430 & 828052 & 14526.6 & 353.926 & 405.348 & 369.942 & 465.533 & 863.757 & 543.019 \\
\hline 80 & 202859 & 1660000 & 29053.1 & 707.851 & 810.697 & 739.883 & 931.065 & 1727.51 & 1086.04 \\
\hline 120 & 304289 & 2480000 & 43579.7 & 1061.78 & 1216.04 & 1109.82 & 1086.78 & 2591.27 & 1629.06 \\
\hline
\end{tabular}

\begin{tabular}{|c|c|c|c|c|c|c|c|c|c|}
\hline \multirow{2}{*}{$\begin{array}{l}\text { Pressure } \\
K N / m^{2}\end{array}$} & \multirow{2}{*}{ Aluminum } & \multirow{2}{*}{ Steel } & \multirow{2}{*}{$\begin{array}{c}\text { Steel } \\
\& \\
\text { Epoxy }\end{array}$} & \multicolumn{3}{|c|}{ CFRP } & \multicolumn{3}{|c|}{ GFR } \\
\hline & & & & Code 1 & Code 2 & Code 3 & Code 1 & Code 2 & Code 3 \\
\hline 40 & $9.55 * 10^{-7}$ & $23.6 * 10^{-7}$ & $27.3 * 10^{-7}$ & $1.09 * 10^{-10}$ & $0.744 * 10^{-10}$ & $0.782 * 10^{-10}$ & $7.62 * 10^{-10}$ & $2.16 * 10^{-10}$ & $2.34 * 10^{-10}$ \\
\hline 80 & $19.1 * 10^{-7}$ & $47.2 * 10^{-7}$ & $54.7 * 10^{-7}$ & $2.18 * 10^{-10}$ & $1.49 * 10^{-10}$ & $1.56 * 10^{-10}$ & $15.2 * 10^{-10}$ & $4.32 * 10^{-10}$ & $4.69 * 10^{-10}$ \\
\hline 120 & $28.6 * 10^{-7}$ & $70.8 * 10^{-7}$ & $82.0 * 10^{-7}$ & $3.28 * 10^{-10}$ & $2.23 * 10^{-10}$ & $2.34 * 10^{-10}$ & $4.70 * 10^{-10}$ & $6.48 * 10^{-10}$ & $7.03 * 10^{-10}$ \\
\hline
\end{tabular}

\begin{tabular}{|c|c|c|c|c|c|c|c|c|c|}
\hline \multicolumn{10}{|c|}{ 7- Failure Criteria (Maximum Stress) } \\
\hline \multirow{2}{*}{$\begin{array}{c}\text { Pressure } \\
K N / m^{2}\end{array}$} & \multirow{2}{*}{ Aluminum } & \multirow{2}{*}{ Steel } & \multirow{2}{*}{$\begin{array}{l}\text { Steel } \\
\text { \& } \\
\text { Epoxy }\end{array}$} & \multicolumn{3}{|c|}{ CFRP } & \multicolumn{3}{|c|}{ GFR } \\
\hline & & & & Code 1 & Code 2 & Code 3 & Code 1 & Code 2 & Code 3 \\
\hline 40 & $1.07 * 10^{-5}$ & $8.64 * 10^{-5}$ & $2.98 * 10^{-5}$ & $4.77 * 10^{-11}$ & $4.10 * 10^{-11}$ & $4.17 * 10^{-11}$ & $12.9 * 10^{-11}$ & $8.90 * 10^{-11}$ & $9.22 * 10^{-11}$ \\
\hline 80 & $2.13 * 10^{-5}$ & $17.3 * 10^{-5}$ & $5.96 * 10^{-5}$ & $9.53 * 10^{-11}$ & $8.21 * 10^{-11}$ & $8.34 * 10^{-11}$ & $25.8 * 10^{-11}$ & $17.8 * 10^{-11}$ & $18.4 * 10^{-11}$ \\
\hline 120 & $3.20 * 10^{-5}$ & $25.9 * 10^{-5}$ & $8.94 * 10^{-5}$ & $14.3 * 10^{-11}$ & $12.3 * 10^{-11}$ & $12.5 * 10^{-11}$ & $18.3 * 10^{-11}$ & $26.7 * 10^{-11}$ & $277^{*}+10^{-11}$ \\
\hline
\end{tabular}



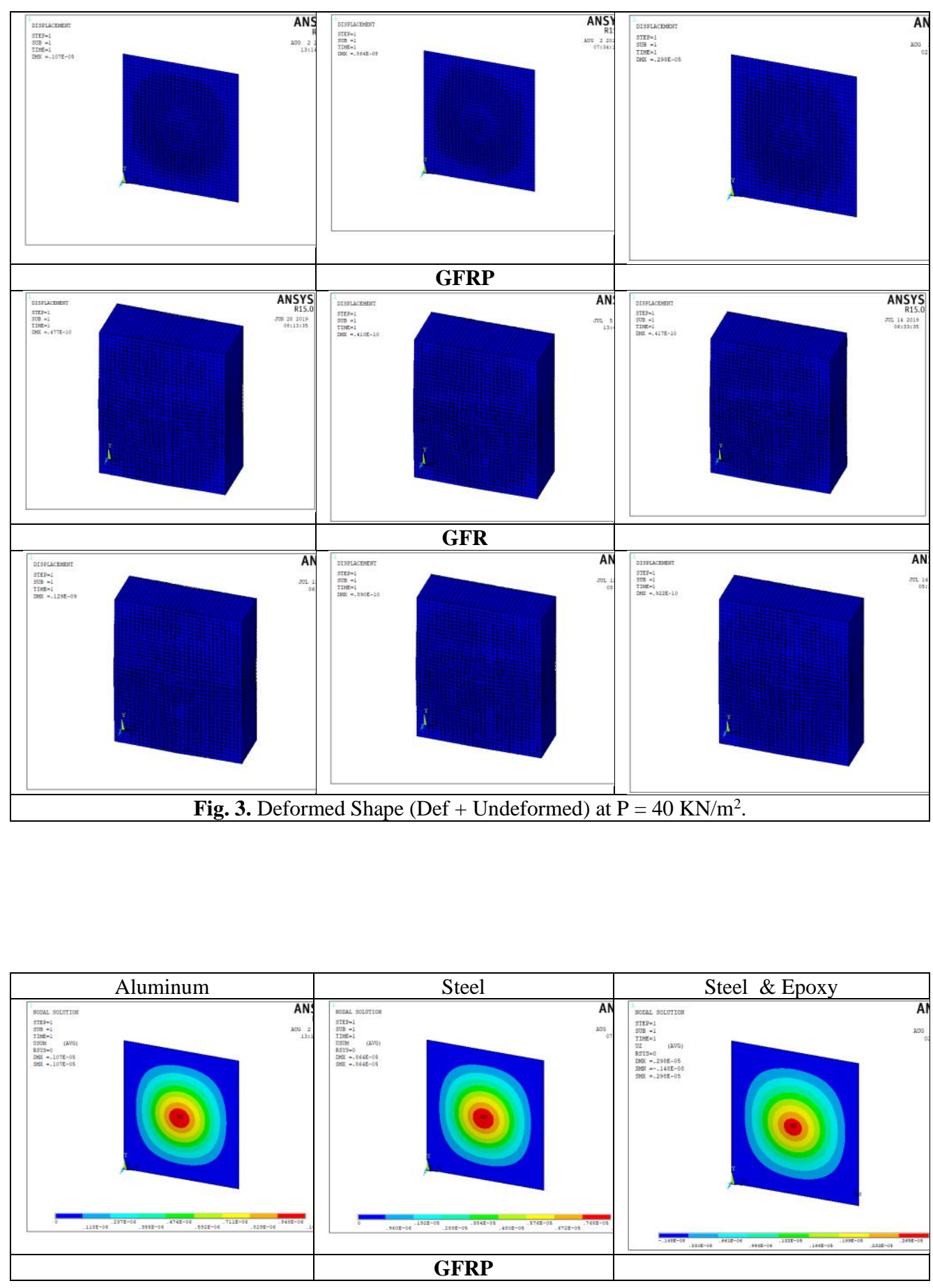


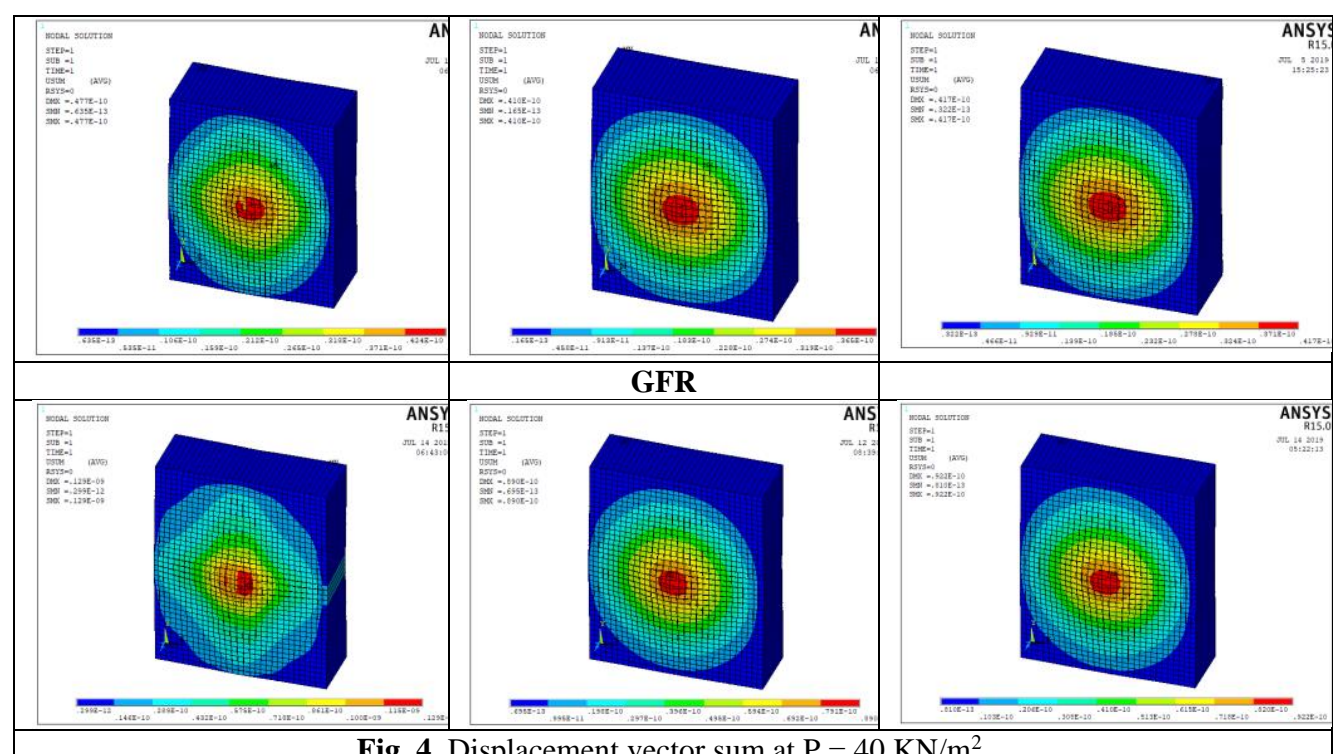

Fig. 4. Displacement vector sum at $\mathrm{P}=40 \mathrm{KN} / \mathrm{m}^{2}$. 

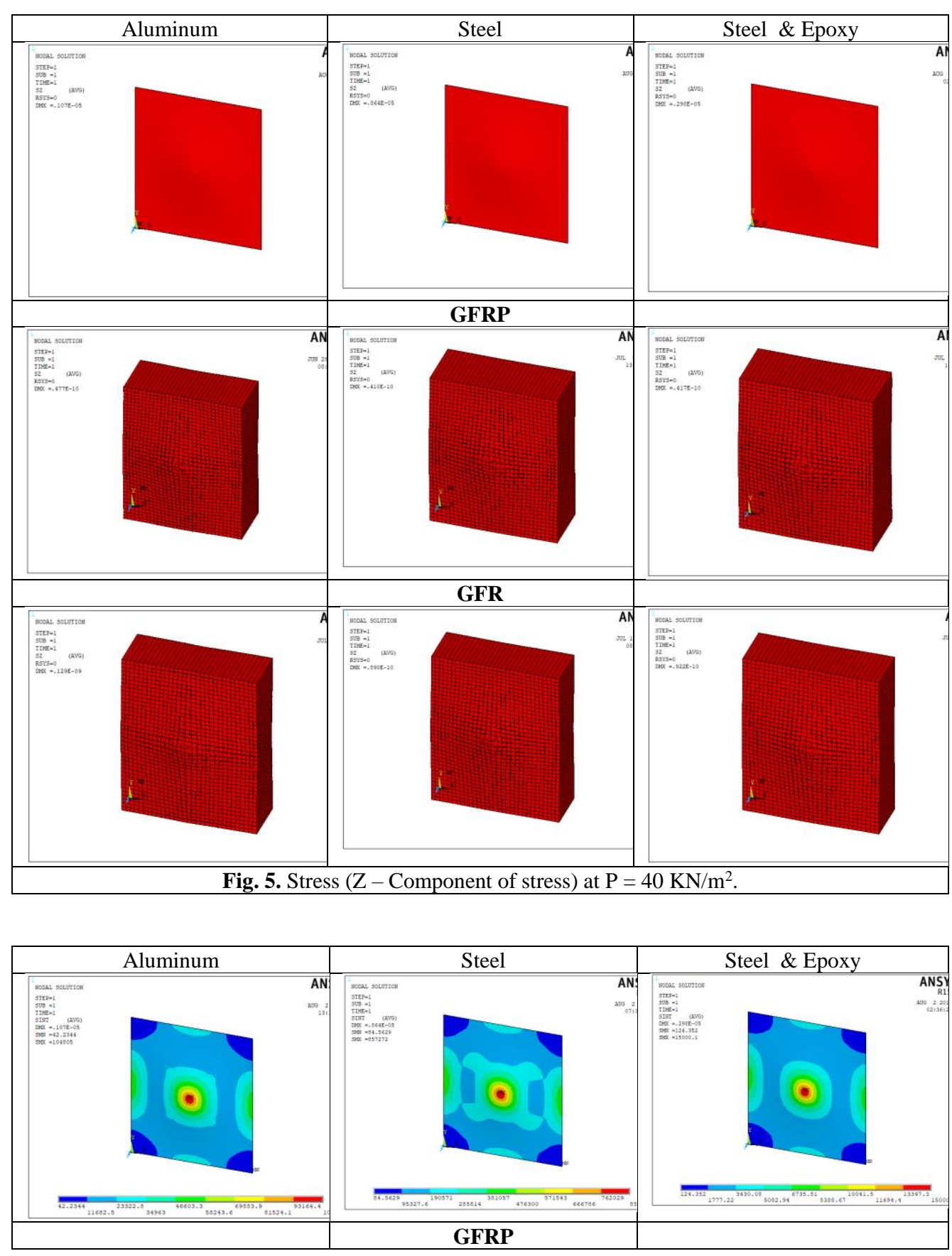


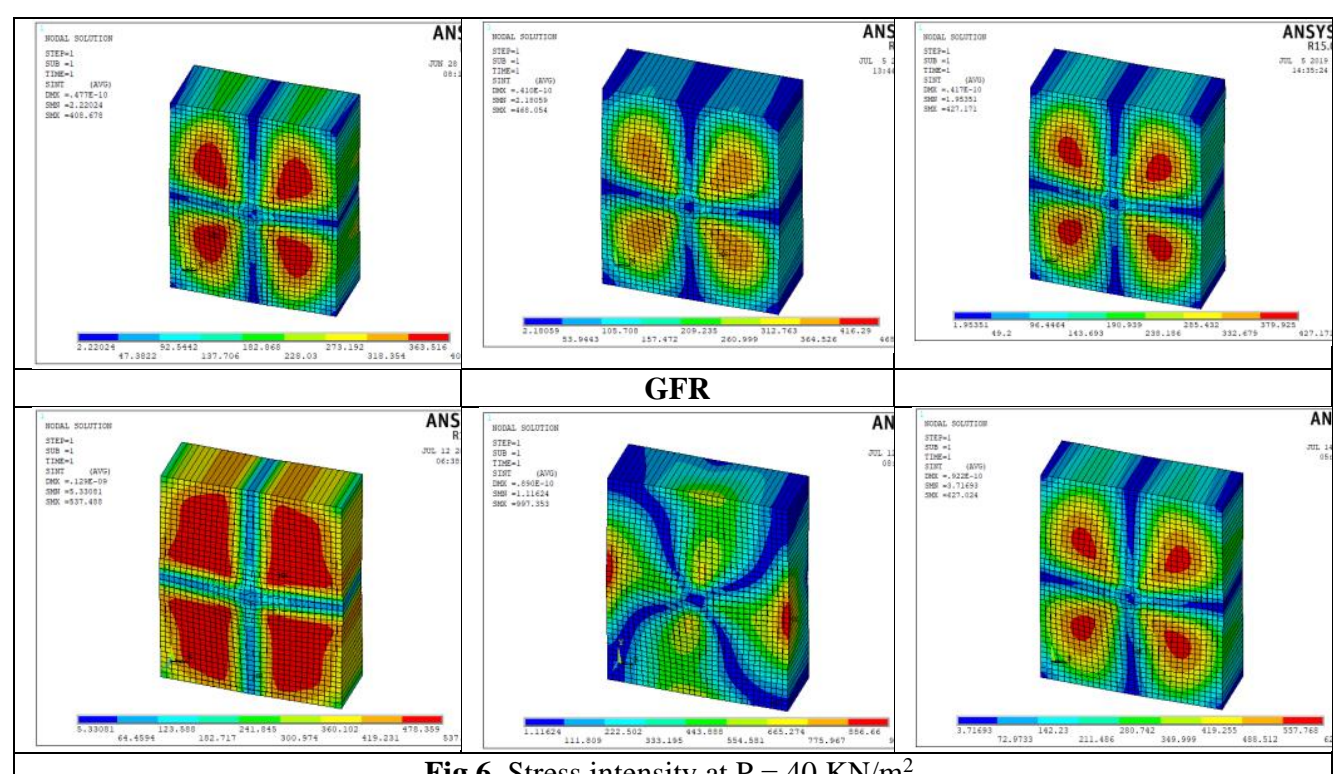

Fig.6. Stress intensity at $\mathrm{P}=40 \mathrm{KN} / \mathrm{m}^{2}$. 


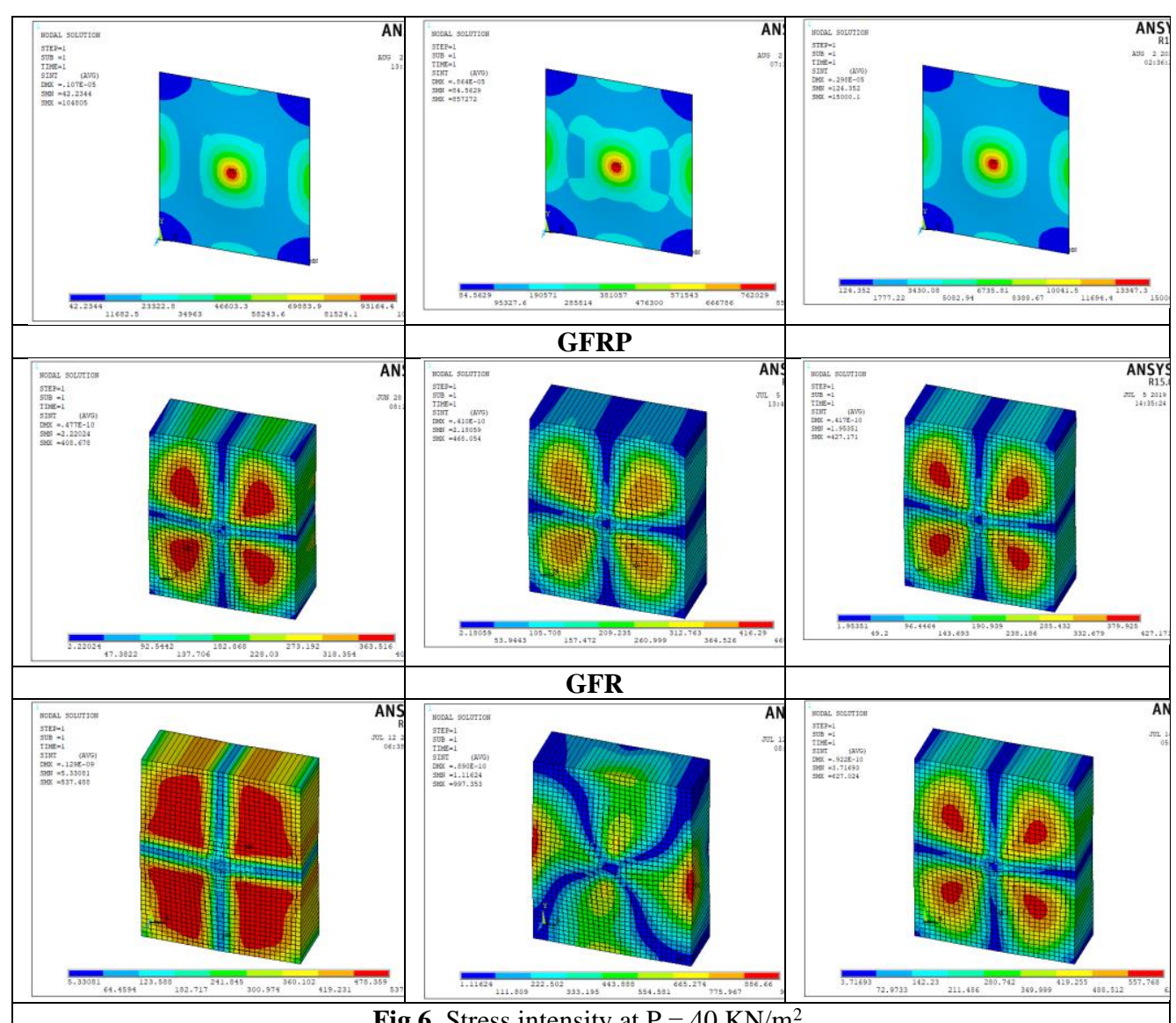

Fig.6. Stress intensity at $\mathrm{P}=40 \mathrm{KN} / \mathrm{m}^{2}$.

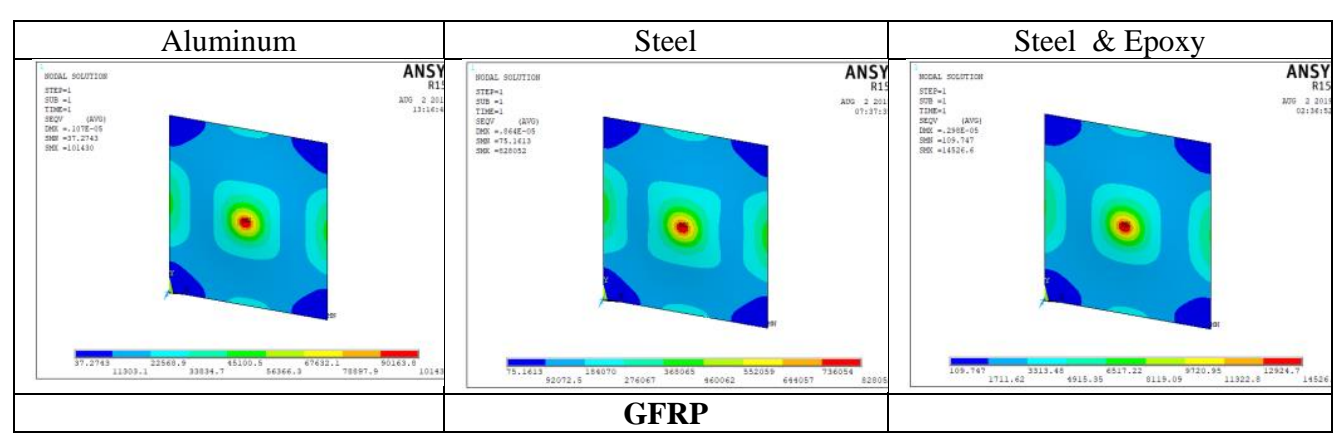



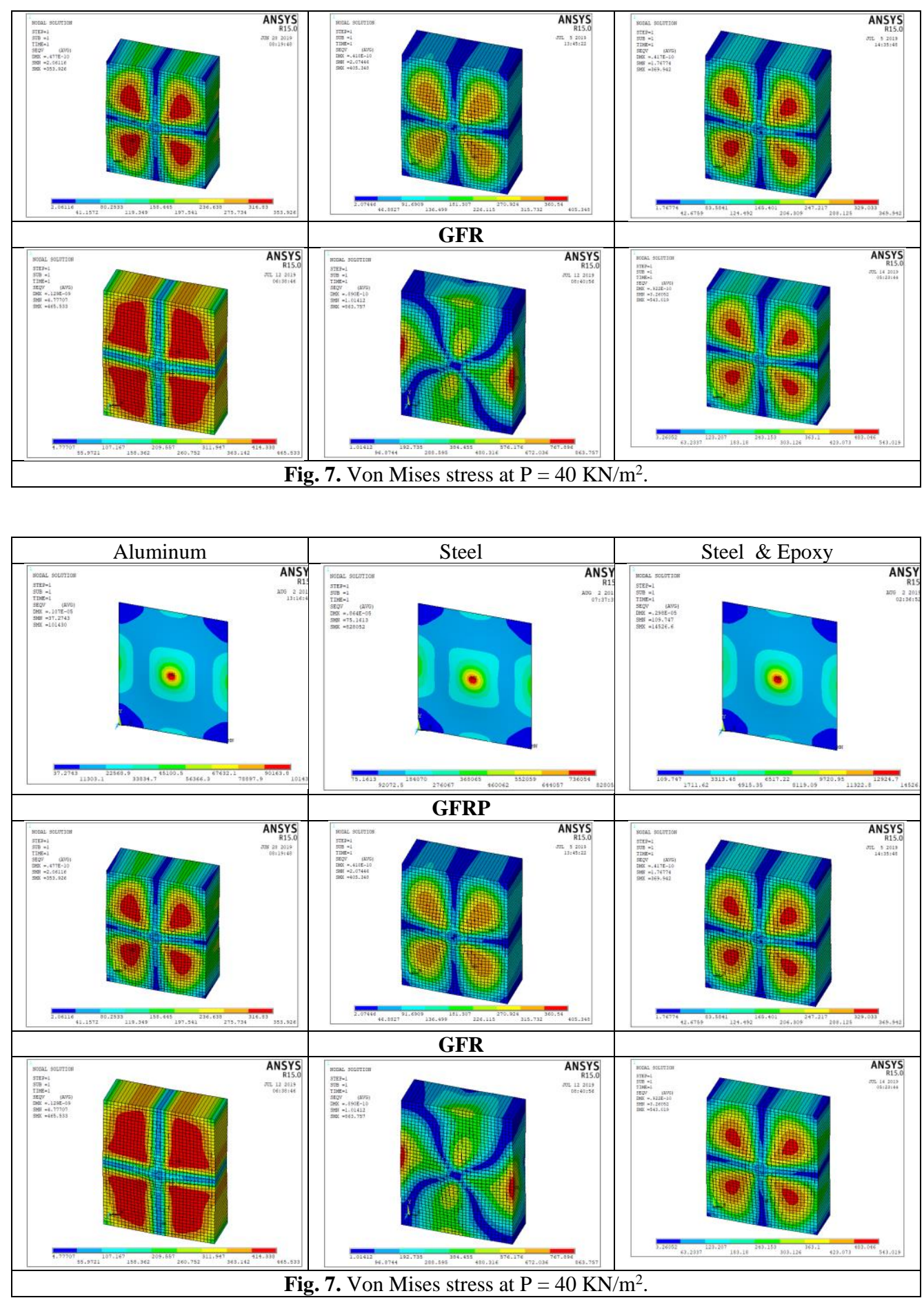


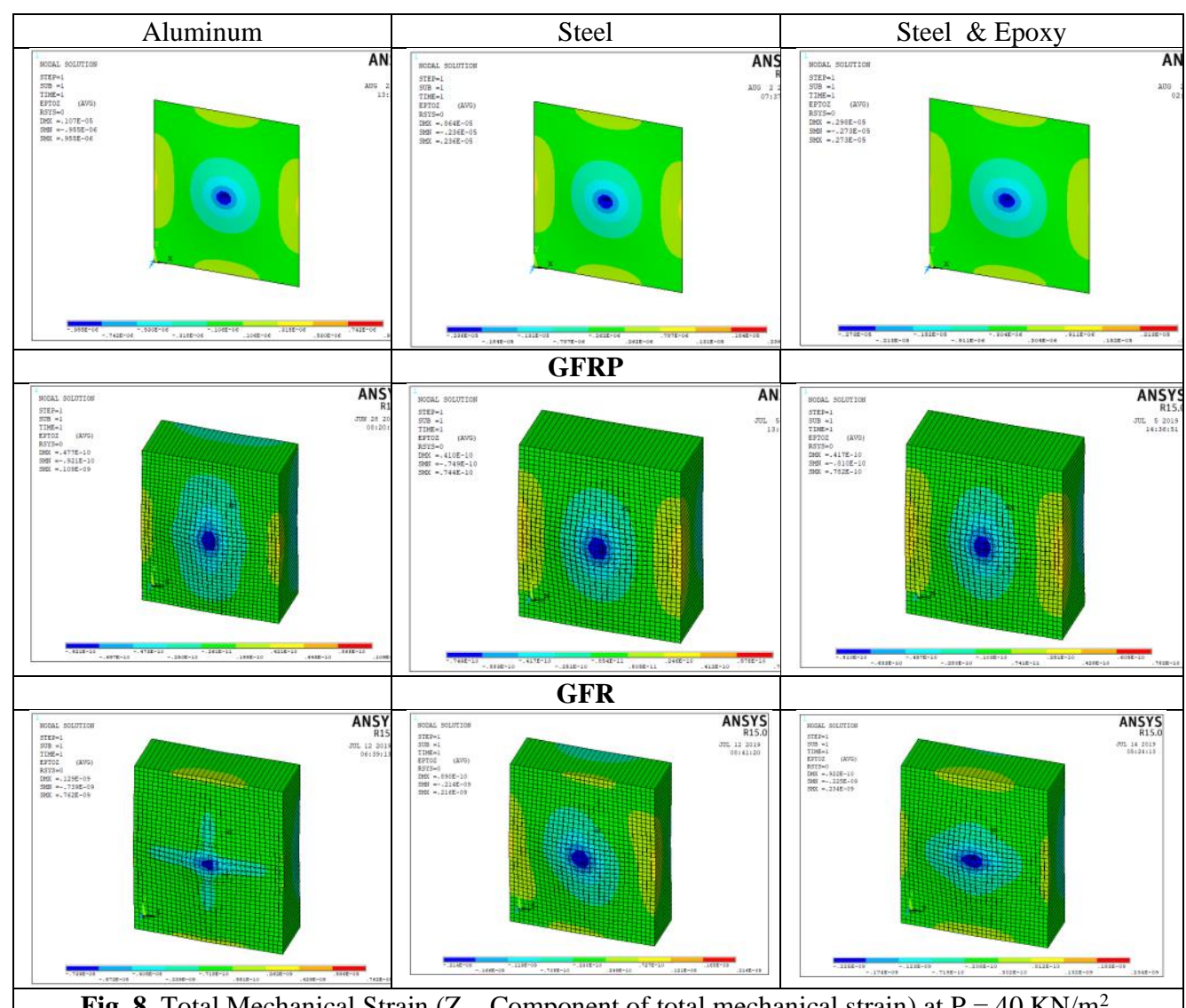

Fig. 8. Total Mechanical Strain $\left(\mathrm{Z}-\right.$ Component of total mechanical strain) at $\mathrm{P}=40 \mathrm{KN} / \mathrm{m}^{2}$.

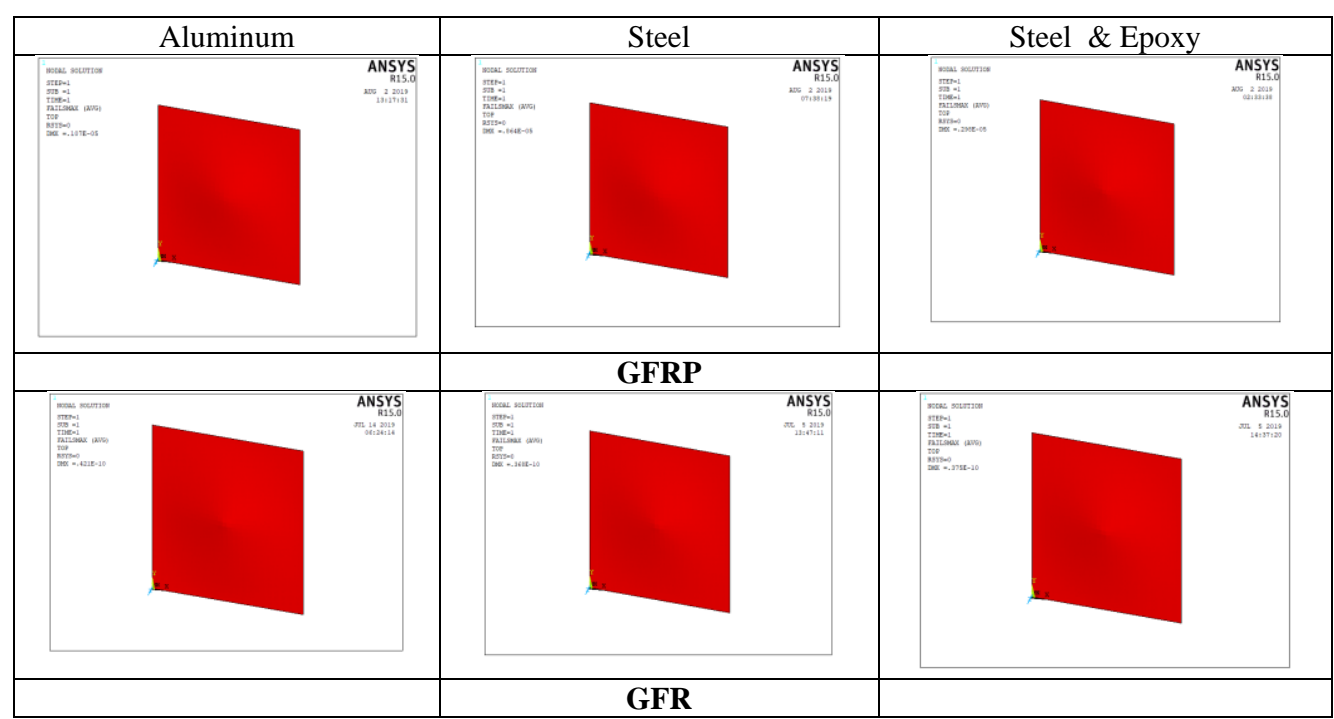




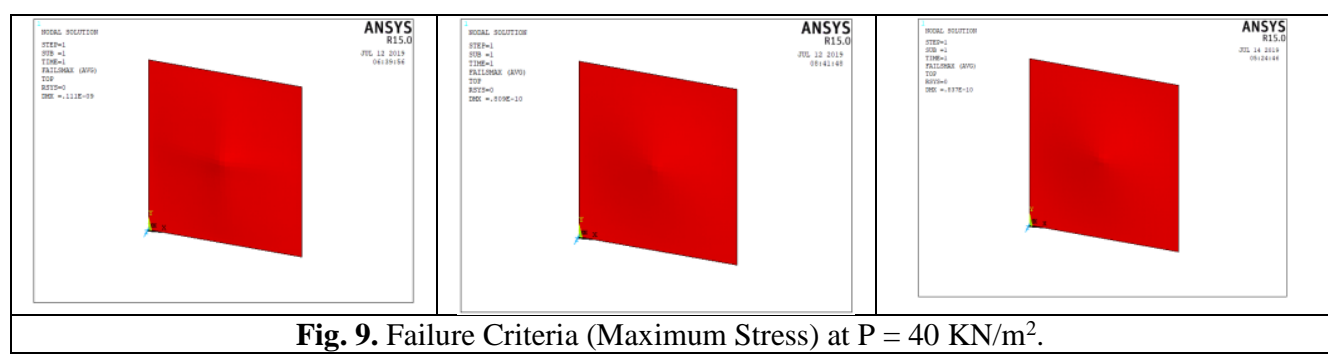

From the analysis of the results in table 4 when the load on the model is doubled or three times, the resistance of the models consisting of mineral and composite materials are doubled in the same proportion of the multiple of the applied load. Also, from the analysis of the results, it was found that the resistance of the composite materials, particularly carbon fiber reinforced ones, is much more than the models consisting of mineral materials due to the increase in the thickness of the model and the high elastic modulus of the models reinforced by carbon fibers. Also as shown in table 4, the best model is the composite material consisting of carbon fiber reinforced, especially the model armed with different angles in the second code. Whereas the least resistant model for the loads was the steel material. The reason for this is that the thickness of the steel model was the lowest $(3.5 \mathrm{~mm})$ because the density of steel high compared to the density of other materials, which made the thickness of the model very small for the same weight taken for all models, which $(5.4 \mathrm{~kg})$ had a larger thickness that was in the component models. It is a composite material due to its low density, which makes it have light weights compared to other materials in addition to the presence of reinforces with a relatively elastic modulus of compared to their weight.

\section{Conclusion}

Based on the results of this study, the following results can be drawn.

1. By comparing the results, it was observed that the best model to resist the loads applied to it is a pattern (CFRP-Mode2), while the poorest model that bears the stresses is the acetylcholine model.

2. After analyzing the results, it was found that the change in the amount of loads applied to the models is directly proportional to the resistance of the models to withstand those loads with the same percentage change.

3. It turns out that the resistance of aluminum models to the loads applied to them is better than the resistance of steel models by more than three times and better than the resistance of the models consisting of epoxy and steel by about twice.

4. Comparing the models consisting of composite materials (CFRP) with (GFR), indicates that the resistance of the models (CFRP- Code1 \& Code2) is greater, especially in models (CFRPCode2).

\section{Acknowledgment}

This research was supported by Engineering Science Research Program through the Northern Technical University / Technical Institute of Mosul funded by the Ministry of Higher Education and Scientific Research / Republic of Iraq. (No. 00363- 2019).

\section{References}

[1] Jane Maria Faulstic de Paiva, Sergio, Mirabel Cerqueira Rezende, "Composition of Tensile Strength of Different Carbon Fabric reinforced Epoxy Composites”, Material research, Vol.9, No. 1, 2006, PP 83-89. 
[2] Xuegang Jia, Yuyan Liu, and Lan Li, “Analysis of Mechanical Properties of Carbon/ Epoxy Composites in the Near Critical water Decompostion”, Polymers \& Polymer Composites, Vol. 21, No. 9, 2013, PP 573.

[3] Ali I. Al-Mosawi, Moslem M. Ali, Salim J. Abbas, "Using of Ansys Program to Calculate the Mechanical Properties of Advanced Fiber reinforced Composites" The Iraqi Journal for Mechanical and Material Engineering, Vol. 12, No. 4, 2012, PP 673.

[4] Puran Singh, Vikas Malik, Priyawart Lather, "Analysis of Composite Materials Used in Bullet Proof Vests using Fem Techniques”, International Journal of Science \& Engineering Research, Volume 4, Issue 5, May-2013, pp 1789 .

[5] Ali I. Al-Mosawi, "Theoretical Evaluation to Tensile strength of Composition material by Using Ansys Program" Journal of Babylon university / Engineering Science/ No. (4)/ Vol.(22):2014, PP989.

[6] Hossein Rahmani, S. Heydar Mahmoudi Najafi and Alireza Ashori, "Mechanical performance of epoxy/ Carbon Fiber laminated Composites", Journal of Reineforced Plastics and Composites, 2014, Vol. 33(8) PP 733-740.

[7] N. Ozsoy, A. Mimaaroglu, M. Ozsoy, M, I, Ozsoy, "Comparison of Mechanical Behaviour of Carbon and Glass Fiber Reinforced Epoxy Composites", proceeding of the 4th International congress APMAS 2014, April 24-27, 2014, fethye, Turkey, ACTA PHYSICA POLONICA A, Vol. 127 (2015), PP1032.

[8] I. K, Yilmazcoban and S. Doner, "Ballistic Protection Evaluation of sequencing the Composite Material Sandwich Panels for the reliable Combination of Armor Layers" Special issue of the 2nd International Conference on Computation and Experimental Science and Engineering (ICCESEN 2015), ACTA PHYSICA POLONICA A, Vol. 130 (2016) PP 342.

[9] John Brightlin T \& Vanishree Beloor, "Impact Analysis of a Composite Laminated using Ansys", International Journal of Advances in Scientific Research and Engineering ( IJASRE ), Vol 02, Issu 05, june-2016, PP15.

[10] Ricardo Baptista, Ana mendão, Mafalda Guedes, Rosa Marat-Mendes, "An Experimental Study on mechanical Properties of Epoxy-Matrix Composition containing graphite Filler”, Procedia Structural Integrity 1, 2016,074 081.

[11] Cathrine HØgmo Strand, "Mechanical and Impact Tests of CFRP”, Master Thesis in Rechnology and Safety in the High North, The Arctic University of Norway, Department of Engineering and safety, June 2017, PP 201-209.

[12] Eyüp Yeter, "Investigation of Ballistic Impact Response of Aluminum Alloy Hybridized with Kevlar/Epoxy Composites", Journal of Polytechnic, 2019; 22 (1): 2019-227.

[13] Weili Wu, Qingtao Wang and Wei Li, "Comparison of Tensile and Compressive Properties of Carbon/ Glass Interlayer and Intralayer Hybrid Compositions”, Materials, 2018, 11, 1105; doi: 10.3390/ ma11071105, PP 196207.

[14] Ali Murat Soydan, Bahadir Tunaboylu, Ahmed Galal Elsabagh, Abdul Kadir Sari, and recep Akdeniz, "Simulation and Experimental Tests of Ballistic Impact on Composite Laminate Armor", Advances in Material Science and Engineering, Volume 2018, Article ID 4696143, PP $42-51$.

[15] Kucher N.K. "Deformation of layered epoxy composites reinforced with unidirectional fibers and satin weave fabric" / N.K. Kucher, M.P. Nemtsov, M.N. Zarazovsky // Probl. strength. - 2006. - No. 1. - C. 41-58 